\title{
Origen de epónimos médicos derivados de la mitología
}

\section{Origin of medical eponyms derived from mythology}

\author{
Alejandro Donoso F. ${ }^{a}$, Mario Vildoso F. ${ }^{b}$, Daniela Arriagada S. ${ }^{a}$ \\ aUnidad de Paciente Crítico Pediátrico. Hospital Clínico Metropolitano La Florida. Santiago. Chile \\ bUnidad de Gestión Clínica del Niño. Hospital Padre Hurtado. Santiago. Chile
}

Recibido el 18 de octubre de 2018; aceptado el 8 de noviembre de 2018

\section{Resumen}

Muchos mitos y leyendas han tenido una profunda influencia sobre el lenguaje médico moderno y están extendidos a todas las especialidades, formando parte de su cultura y de la historia de la Medicina. Este artículo revisa en forma breve la historia de algunos epónimos los cuales son empleados habitualmente en medicina. Es conocimiento de pocos el origen mitológico en su denominación.

\section{Abstract}

Many myths and legends have had a profound influence on modern medical language and are extended to all specialties as part of their culture and the history of medicine. This article briefly reviews the history of some eponyms which are usually used in medical practice. It is the knowledge of a few the mythological origin in its denomination.
Palabras clave:

Epónimos;

mitología; humanidades; historia de la medicina; mitología y medicina

Keywords: Eponyms; mythology; humanities; medicine history; mythology and medicine

\section{Introducción}

"Juro por Apolo el médico y Esculapio y por Hygeia y $\mathrm{Pa}$ nacea y por todos los dioses y diosas...". En el juramento hipocrático a quién primero se invoca es a Apolo, inventor del arte de curar y médico de los dioses. Por otra parte, su hijo Asclepio o Esculapio para los romanos, dios de la salud por antonomasia en la civilización griega, fue educado por el centauro Quirón quién le enseñó las artes curativas. Se señala que logró tal habilidad, no midiendo su auténtico poder, que incluso podía devolver la vida a los muertos. Su abuelo,
Zeus, temeroso que el más allá quedara despoblado, lo fulminó con un rayo, tras lo cual los hombres lo ascendieron a la categoría de deidad olímpica ${ }^{1}$. Entre su descendencia en la Tierra está Higiea, cuyo nombre perdura hasta la actualidad en la palabra higiene, Panacea quién era símbolo del tratamiento y Telesforo quién representaba la convalescencia.

Como se observa, la relación entre nuestra medicina occidental y mitología está presente a lo largo de la historia de la humanidad. En el ámbito del cuidado intensivo se utilizan frecuentemente diversos epónimos derivados de la mitología. Sin embargo, por quienes los emplean, existe escaso

Correspondencia:

Alejandro Donoso F

adonosofuentes@gmail.com 
conocimiento sobre su origen. A continuación, se revisa en forma breve algunos de ellos, con el objetivo de crear interés en la historia de la medicina, enriquecer el lenguaje médico y humanizar nuestra labor diaria.

\section{Atropina}

Durante los tiempos del Imperio Romano y en la edad Media, la atropina se utilizó en forma frecuente para producir envenenamiento de causa desconocida y de lenta evolución. Esto hizo que el naturalista y botánico sueco Carlos Linneo (1707-1778) denominara a esta planta Atropa belladonna (Species Plantarum, 1753), en referencia a Átropos (figura 1) ('A $\tau \rho \circ \pi \circ$, "inexorable", "inevitable", "que nadie puede escapar”) la más antigua de las tres Parcas, quién era la cortadora del hilo de la vida y es a quien va referida la expresión "la Parca" en singular. La conexión semántica entre la mortal Parca y la planta mortífera es, por lo tanto, obvia, si uno rastrea un poco el trasfondo mitológico ${ }^{2,3}$.

Estas divinidades representaban el destino de los mortales y controlaban el metafórico hilo de la vida (desde el nacimiento hasta la muerte) en especial su duración y los sufrimientos que estos debiesen padecer. Sus equivalentes en la mitología griega eran las Moiras (significa literalmente parte o porción) quienes se aparecían tres noches después del nacimiento de un niño para hilar su hilo y así determinar el curso de su vida.

La anciana Átropos elegía el mecanismo de la muerte y terminaba con la vida de cada mortal cortando su hebra con sus "aborrecibles y largas tijeras" sin discriminar por edad, riqueza o cualquiera otra consideración. Trabajaba junto con Cloto ("hilandera"), la primera y la más joven, quien hilaba la hebra de la vida con una rueca y un huso, y Láquesis ("la que echa a suertes"), quien medía con su vara la longitud del hilo de la vida y asignaba el destino. Las tres eran hijas de Zeus y Temis y se las representa como a tres mujeres hieráticas vestidas con túnicas blancas, tres pálidas viejas hilanderas o tres damas de distintas edades.

Asimismo, el nombre belladonna deriva del uso de este preparado (jugo de las bayas) por las mujeres italianas renacentistas para dilatarse las pupilas. No obstante, se tiene constancia de esta práctica en el Antiguo Egipto.

En 1831, el farmacéutico Heinrich Mein logró desarrollar el aislamiento en forma cristalina pura de la atropina. A su vez esta fue sintetizada por primera vez por el alemán Richard Willstätter en 1901, quién después ganaría el premio nobel de química por sus trabajos sobre la estructura de la clorofila y otros pigmentos vegetales (1915).

\section{Ecografía}

El origen de la palabra "eco" viene de la mitología griega, concretamente del mito de Eco y Narciso (figura 2). Eco era una ninfa del bosque, la cual dado su facundia, fue castigada por la diosa Hera con la imposibilidad de hablar, pudiendo repetir sólo la última palabra que pronunciaba su interlocutor. Este castigo se debió a que Eco encubría las infidelidades de Zeus hacia Hera, entreteniéndola con sus elocuentes conversaciones.

Un día se enamoró del hermoso y presumido joven Narciso a quién vio en el bosque, pero no se atrevió a

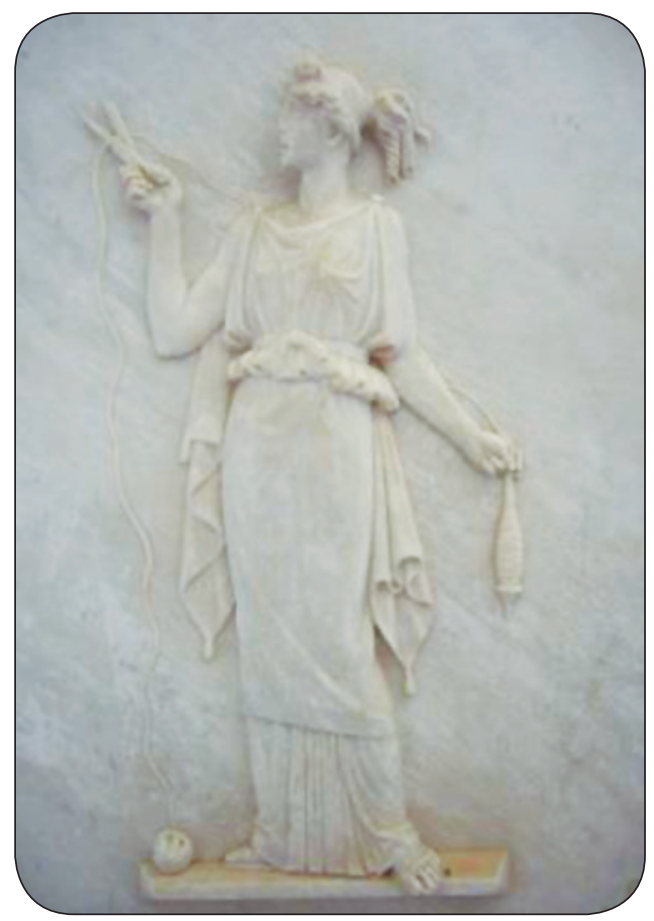

Figura 1. Relieve de Átropos cortando la hebra de la vida.

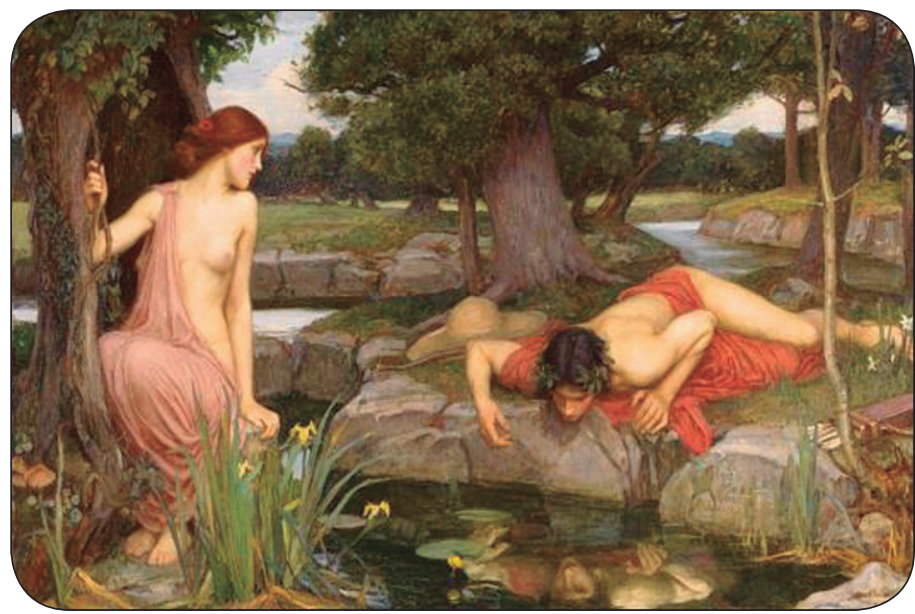

Figura 2. "Eco y Narciso". John William Waterhouse, 1903. 


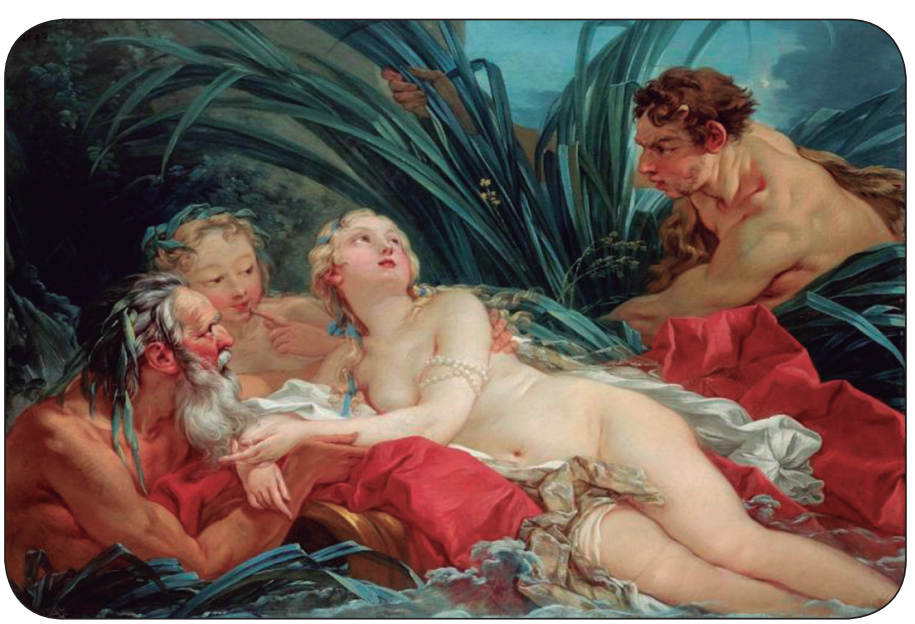

Figura 3. "Pan y Siringa". François Boucher, 1743.

Figura 4. "Eos". Evelyn de Morgan, 1895.

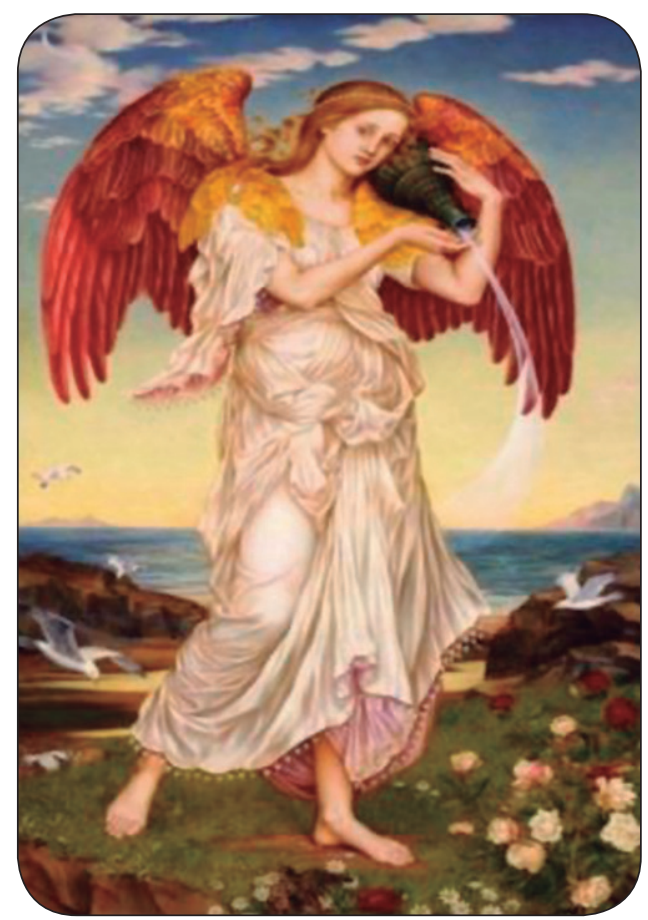

acercarse a él, escondiéndose entre los arbustos. Narciso al darse cuenta de esta situación, le hacía preguntas, pero ella solo respondía con las mismas palabras de él, transformándose en un diálogo imposible. Finalmente, ante el rechazo de Narciso ella ofendida y desolada decide escapar hacía un lugar solitario dejando de comer y de cuidarse. Así, su vida se fue consumiendo poco a poco por el dolor, desintegrándose finalmente en el aire, quedando solo su voz, la que repetía las palabras de cualquier persona.

En el año de 1917 se efectuó la primera aplicación tecnológica del ultrasonido, la cual fue para la ubica- ción de submarinos (hidrófono), mientras que en 1942 Karl Theodore Dussik, un neurólogo y psiquiatra austriaco fue el primero en emplearlo en el ámbito de la medicina para el diagnóstico de tumores cerebrales ${ }^{4,5}$.

\section{Siringomielia}

En las Metamorfosis I, cuenta el poeta romano Ovidio (43 a.C. - 17 d.C.) que la bella náyade Siringa de Arcadia (lugar paradisíaco de vida bucólica), una de las ninfas de los cuerpos de agua dulce, escapaba del sátiro Pan (figura 3) (hijo de Hermes y una cabra), fauno con rostro, torso y brazos de hombre y patas de macho cabrío, quién se había enamorado profundamente de ella. Tratando de esconderse entre la vegetación a orillas del río Ladón, suplicó a sus hermanas las ninfas del río que la transformasen, siendo entonces convertida en junco de cáñamo. Pan la buscó desesperadamente, pero fue incapaz de identificarla de las otras plantas fluviales y al suspirar sobre las cañas solo escuchó un agradable sonido, parecido a un lamento, por lo que decidió trocear una caña, unió sus partes con cera construyendo un instrumento musical (flauta). Cautivado por la dulzura de su son, el dios habría dicho: “Esta será mi forma de hablar contigo!”. Así, el instrumento hecho de cañas desiguales conservó el nombre de la muchacha ${ }^{6}$. Con esta flauta en la mano suele aparecer el sátiro representado.

Pan además es considerado el responsable de los ruidos terribles de origen desconocido escuchados en los bosques y montañas originando la palabra pánico ${ }^{7}$.

La siringomielia, que literalmente significa "cavidad dentro de la medula espinal", corresponde a una condición crónica y progresiva ocasionada por una alteración en el flujo del líquido cefalorraquídeo, desarrollando síntomas al crecer de tamaño. En la mayoría de los casos, se asocia a la malformación de ArnoldChiari ${ }^{8}$. La descripción inicial de esta cavitación medular ocurrió en 1546 por el anatomista francés Charles Estienne (1504-1564) pero este término fue empleado por primera vez en 1824 por el patólogo francés Charles-Prosper Ollivier d Angers ${ }^{9}$.

\section{Eosinófilo}

En la mitología griega, Eos diosa del amanecer y del alba (figura 4), es la hija menor de los titanes Hiperión y Tea, hermana del dios del sol Helios y de la diosa de la luna Selene. Es representada como una hermosa diosa alada cuyos dedos rosados abren las puertas del infierno y permiten que pase el carro de Helios. Según la Ilíada de Homero lleva un manto color azafrán bordado con flores. Todas las mañanas, tras despertar salía del borde del océano, donde vivía, subía al cielo para volcar sobre la tierra el rocío matinal (sus lágrimas), 
iluminar al mundo y anunciar a Helios. Transcurrido el día y antes de la puesta del sol, se desplazaba por el cielo en una cuadriga tirada por los caballos Faetón y Lampos.

Eos era tan bella, que tuvo muchos amores, tanto titanes como mortales. Con Astreo fue madre de los cuatro vientos, los planetas y Eósforo (el lucero del alba). Condenada por Afrodita al enamoramiento eterno, secuestró con fines amorosos a Ganimedes, Céfalo, Clito y Titono, este último, entre sus amantes, el más fiel e importante. Para poder estar permanentemente juntos, Eos le pidió a Zeus que le diese el don de la inmortalidad a Titono, pero se olvidó de pedir también la eterna juventud. Así, el infortunado Titono sufrió un deterioro extraordinario al vivir eternamente hasta convertirse en una cigarra. Ante esto, Eos se despertaba al alba cada mañana para así evitar verlo.

Este leucocito diferenciado fue descrito por Paul Ehrlich en 1879 al observar en sangre periférica la existencia de unas células que contenían gránulos muy brillantes. El Dr. Ehrlich es considerado el padre de la quimioterapia y fue premio nobel de medicina en 1908.

\section{Mercurio}

Debido a la característica movilidad del metal, se le asignó el nombre del Dios romano Mercurio (figura 5), hijo de Júpiter y de Maia Maiestas. Era el dios del comercio (merx en latín significa "mercancía”), protector de comerciantes, pastores y viajeros, además de ser un ágil e inquieto mensajero de los dioses. Ovidio señala que Mercurio era el encargado de llevar los sueños de Morfeo desde el valle de Somnus a los humanos mientras estos dormían. Se representa habitualmente como un joven desnudo, con su calzado provisto de alas (talarias) y un casco alado (pétaso), quién además porta un caduceo.

El origen del símbolo $\mathrm{Hg}$ proviene de la palabra latina "hydrargyrum", que significa "agua de plata" o "plata líquida”, aludiendo al aspecto plateado del metal y a su estado líquido a temperatura ambiente lo cual llamaba poderosamente la atención.

\section{Hipnótico}

En la mitología griega, Hipno o Hipnos (“sueño", "sopor") es la personificación del sueño. Era hijo de Nix, diosa de la noche y hermano gemelo de Tánatos (muerte $)^{10}$. Interesantemente se puede aquí apreciar como los conceptos de sueño y muerte parecen estar estrechamente asociados.

Hipnos vivía en una cueva oscura donde el sol nunca brillaba y en cuya entrada crecían amapolas entre otras plantas. Según otras fuentes, residía bajo una isla griega, a través de la cual pasaba el río Lete (río del olvido, uno de los cinco ríos del Hades). Con Pasítea tuvo mil hijos, los Oniros. Los tres más importantes aparecían en los sueños de los reyes: Morfeo (dios de los sueños), Fobétor (quién causa miedo y crea bestias en los sueños) y Fantaso (dios de la fantasía y la imaginación).

En el arte, Hipnos es retratado como un hombre joven desnudo y con alas en los hombros o las sienes. Sus atributos incluyen un cuerno de opio inductor de sueño, un tallo de amapola, una rama de la que gotea el rocío del río Lete y una antorcha invertida. Morfeo es su principal ayudante y evita que los ruidos lo despierten.

Los nombres con el prefijo "Hypn" fueron propuestos por el magnetizador francés Étienne Félix d'Henin de Cuvillers en 1821.

\section{Morfina}

Fue aislada del opio en 1804 por el farmacéutico Friedrich Wilhelm Sertürner (1783-1841) escogiendo el nombre del dios griego de los sueños Morfeo ("forma”), hijo del dios del sueño Hipnos ${ }^{11}$. Morfeo, principal de los Oniros, tomaba la forma de seres humanos, especialmente la de sus seres queridos, y se aparecía en los sueños de los mortales (reyes y emperadores). Era representado con alas que batía rápida y silenciosamente, lo que le permitía volar en forma veloz a cualquier rincón de la Tierra.

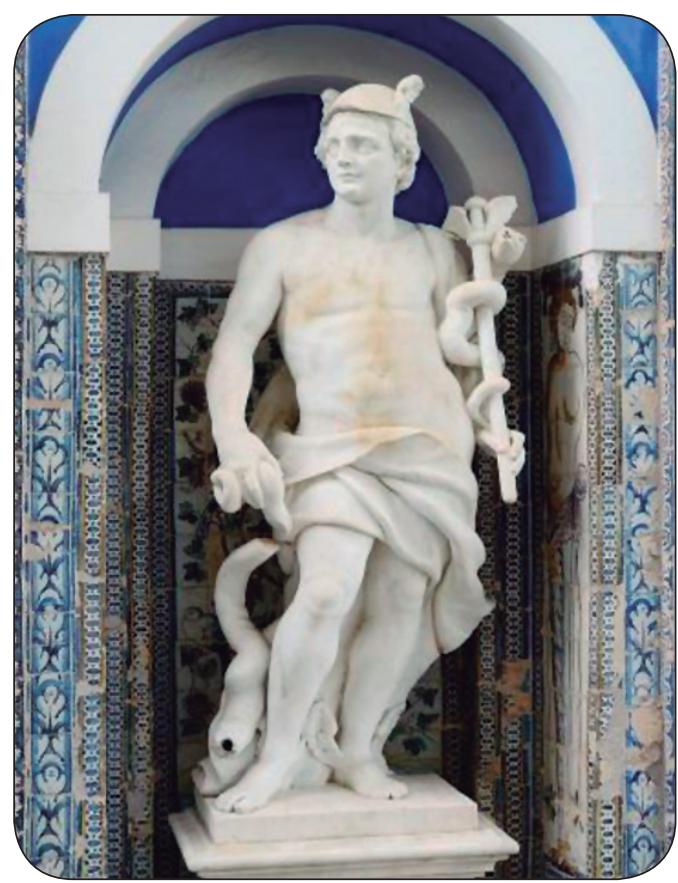

Figura 5. Mercurio. Palacio Fronteira, siglo XVII. Lisboa, Portugal. 
Figura 6. "Higea" P. P. Rubens, ca 1615.

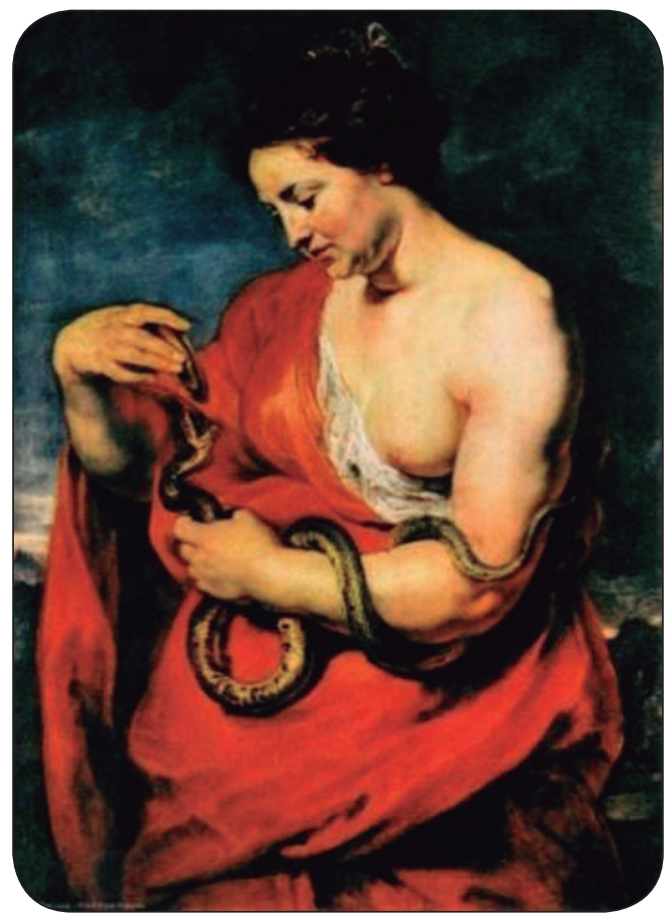

\section{Higiene}

Higia, (Higiea o Higeia), era hija de Asclepio, nieta de Apolo y hermana de Panacea, siendo diosa de la curación, limpieza y sanidad (figura 6). Higia siempre acompañaba a su padre médico y lo ayudaba en la recuperación del paciente. Aunque tenemos referencias de Higia desde el s. VII a.C., su culto formal no fue instaurado hasta las epidemias que asolaron Atenas entre los años 429 y 427 a.C. Tras la epidemia de Roma (293 a.C.) se introdujo su culto en Roma, donde también se la conocía con el nombre de "Salus". Se la suele representar como a una mujer joven con una gran serpiente enroscada en su cuerpo y a quién intenta dar las prepa-

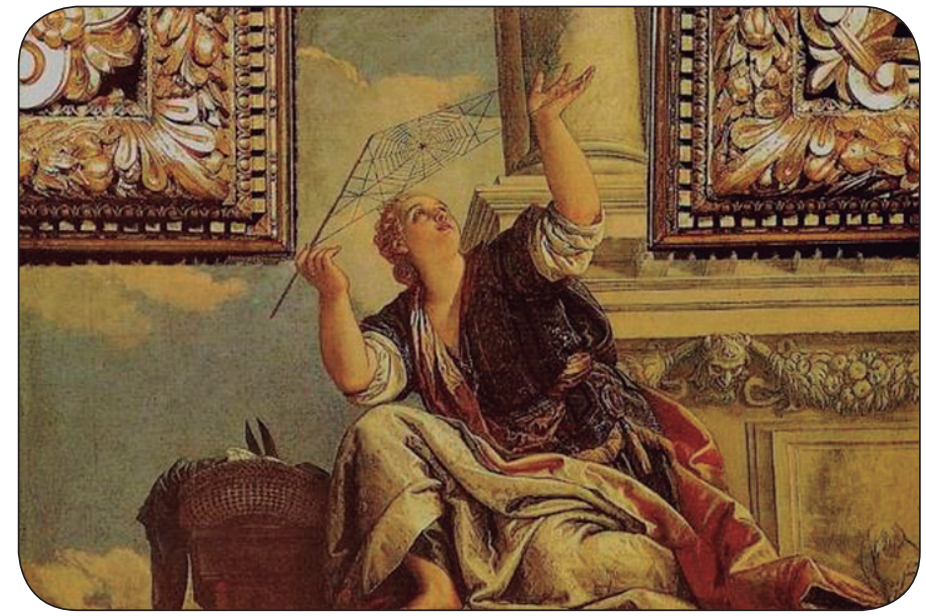

Figura 7. "Aracnes". Paolo Veronese, 1520. raciones medicinales desde un recipiente en su mano. Destacan las pinturas de G. Klimt ("Hygeia", 1901) y P.P. Rubens ("Higea, diosa de la salud"; ca 1615) sobre ella.

\section{Quirófano, quirúrgico}

Mientras el resto de los centauros eran bestias muy rudas e impetuosas, el inmortal Quirón $(\chi \varepsilon i \rho \omega v)$ o Queirón, cuyo nombre proviene de la palabra griega $\chi \varepsilon \imath \rho$, que significa "mano"12 se distinguía por su prudencia, buen carácter, sabiduría, habilidad manual, inteligencia y fraternidad. Este centauro, era hijo de Cronos (Saturno) y la ninfa Filira. Fue esta última quién le suplicó a Zeus luego del parto que la convierta en tilo, para no amamantar a semejante criatura. Así, Quirón creció en una gruta a los pies del monte Pelión, en Tesalia, en manos de Apolo y Atenea, sus padres adoptivos.

Fue educador en música, arte, poesía, caza, moral, medicina y cirugía, y tutor de varios de los héroes destacados de la mitología griega. El famoso centauro Quirón fue quién enseñó, por encargo de Apolo, las artes curativas a Esculapio ${ }^{13}$.

Era el rescatador de la muerte y se dedicaba a socorrer a los heridos del campo de batalla, sin necesidad que estos le rindiesen pleitesía; además contaba con el poder de la premonición, sin embargo, no podía modificar el destino marcado por las Parcas. Los héroes de la Ilíada no dejaban de alabar las pócimas de hierbas con que trataba las heridas de guerra.

Quirón, fue herido accidentalmente por Hércules con una flecha sumergida en el veneno mortal de la Hidra de Lerna, mientras este luchaba con otros centauros. La flecha se introdujo en su pierna, en su parte equina, y aunque él mismo proporcionó el remedio para la cura, la herida era insanable. No obstante, no puede morir por su naturaleza inmortal, pero tampoco tolerará los dolores eternos. Ante esto, pacta con Zeus, intercambiar su vida por la de Prometeo (regalándole su inmortalidad), quien se encontraba castigado por haber robado el fuego del Olimpo para dárselo a los mortales, permaneciendo atado a una piedra mientras un águila se comía sus vísceras eternamente. Al liberarlo, termina el sufrimiento de Quirón descendiendo sin dolor al Averno, el mundo de los muertos. Luego de esto, Zeus decidió situarle en el firmamento como la constelación del Centauro o Sagitario.

En la actualidad, Quirón es reconocido como una de las deidades primigenias de la salud. Se señala en la dualidad de su naturaleza una metáfora sobre el quehacer médico enfocado hacia una práctica integral, mediante la evaluación e intervención de elementos objetivos, subjetivos y anímicos del paciente. 


\section{Aracnoides}

Aracne era la hija de Idmón de Colofón (figura 7), un tintorero de lanas. Esta joven adquirió gran fama por su habilidad como tejedora de tapices, motivo por el cual era permanentemente alabada, empero, esto le causó también gran soberbia, llegando incluso a desafiar a la misma diosa Atenea (diosa de la sabiduría y las Artes). La diosa se enfadó, dando a Aracne una oportunidad de redimirse. Disfrazada de anciana, advirtió a Aracne que no ofendiese a los dioses, sin embargo, la mortal se burló y propuso un concurso de tejido en el que pudiera demostrar su superioridad. Atenea elaboró el suyo basado en la escena de su victoria sobre Poseidón (este fue el motivo de que los ciudadanos de Atenas nombraran con su nombre a la ciudad) y, según lo relatado por Ovidio, Aracne tejió un tapiz sobre los amores de los dioses del Olimpo, en particular sobre las infidelidades de Zeus (padre de Atenea). Esto encolerizó a Atenea quién destruyó el telar y tapiz de Aracne decidiendo finalmente, según algunas versiones, convertirla en una araña; pero otros autores relatan que Aracne se ahorcó, ante el castigo al cual era sometida, y Atenea, apiadándose de ella, decidió conservarle la vida, pero la maldijo, convirtiéndola en araña que hila $y$ teje eternamente.

Fue el médico y anatomista holandés Gerard Blasius quien descubrió y nombró en el año 1664 a la membrana aracnoides como tal. Antes de su descubrimiento, los conceptos de producción de fluido cerebroespinal, circulación y absorción no existían ${ }^{14}$.

\section{Anamnesis}

Mnemósine o Mnemósina es la deidad griega de la memoria. Es una titánide, hija de Gea y Urano, en su tiempo reconocida como una de las divinidades con más poder porque sabía "todo lo que ha sido, todo lo que es y lo que será", como menciona Hesíodo ${ }^{15}$. Zeus, en sus correrías engendrará en ella, durante nueve noches de amor consecutivas a las nueve Musas.

Mencionado por Laín Entralgo en La Historia Clínica Hipocrática: "Ante el enfermo, el buen médico debe conocer y decir lo que es, lo que ha sido y lo que será. Ha de hacerlo, por añadidura, con mayor certidumbre y precisión que el paciente mismo. La anamnesis no sería tan sólo un método para indagar lo que en el pasado del enfermo importa, sino una prueba de suficiencia técnica y profesional, un ejercicio en que el médico muestra al enfermo que es capaz de conocer su enfermedad más profunda y exactamente que él, y del cual obtiene datos para establecer un pronóstico certero" ${ }^{\prime \prime}$.

\section{Hemorragia, hemodiálisis, hematocrito}

En griego, hemo ( $\alpha \dot{\mu} \mu \alpha)$ es una palabra que significa sangre. Probablemente su nombre proviene de una de las dos siguientes historias.

El monte Hemo se encuentra en la región de Tracia en la frontera greco-búlgara. Se cuenta que, en venganza por la destrucción de los gigantes, la Madre Tierra (Gea) engendró con Tártaro a Tifón, su hijo menor y el monstruo más grande que haya existido. Este tenía cabeza de asno, extremidades inferiores formadas por serpientes enroscadas y manos con innumerables cabezas de ofidios. Por su poder y forma monstruosa ocasionó la estampida de los dioses del Olimpo, incluyendo a Zeus. Tifón logró despojar a Zeus de su hoz de pedernal y cortándole los tendones de las manos y los pies, lo inmovilizó encerrándolo en la Cueva Coricia. Sin embargo, Zeus era inmortal y luego de recibir la ayuda de Hermes y Pan, recuperó sus tendones y con ello su movilidad, persiguiendo a Tifón en su carro. En Tracia, Tifón se defendió de Zeus lanzándole montañas, pero éste interponía sus rayos haciendo que éstas rebotasen y golpearan a Tifón provocándole heridas profundas, cuyos chorros de sangre dieron el nombre al monte Hemo. Finalmente, Tifón fue derrotado y encerrado en el interior del volcán Etna, cuyo cráter expulsa fuego hasta nuestros días ${ }^{17}$.

En la historia de Antígona, la hija de Edipo y Yocasta, decide dar sepultura a su hermano Polinices, contrariando las órdenes de Creonte, su tío y rey, luego que su hermano muriera luchando por el trono de Tebas. Polinices era considerado un traidor para Creonte y como tal no es merecedor de una sepultura digna; no obstante, Antígona piensa lo contrario y obedeciendo las leyes divinas, por sobre el edicto real, lo sepulta. Cuando es sorprendida por el rey, este la condena a morir sepultada viva y ordena a su hijo Hemón, novio de Antígona, a que ejecute la orden. Hemón no consigue que su padre recapacite y huye del lugar del sacrificio para no ser testigo de ese trágico momento, no obstante, Antígona se suicida. Creonte se arrepiente tardíamente, a instancias del vidente Tiresias, pero cuando llega al lugar de la inmolación de Antígona, Hemón ataca a su padre, y al no conseguir matarlo, se suicida con su espada, ensangrentando las mejillas de Antígona ${ }^{18}$.

\section{Discusión}

Los griegos usaban el vocablo mito, término que en su origen significaba "palabras", para referirse a los relatos propios de la imaginación del pueblo ${ }^{19}$. Generalmente eran historias coherentes sobre seres divinos destinadas a explicar algo y los cuales estaban vincu- 
lados con la religión ${ }^{1}$. Los poetas griegos Homero y Hesíodo son reconocidos como los precursores de la mitología griega.

Como se aprecia en la presente comunicación, la mitología, especialmente la grecorromana, la cual desarrolló su propia cosmogonía, fue una fuente inagotable de diversos epónimos, muchos en uso actualmente. Más específicamente, entre los siglos XVI y XX, decenas de figuras de la literatura griega y romana ingresaron a la terminología de las ciencias médicas. Algunas de estas expresiones tienen un uso clínico vigente ( $\mathrm{Ca}$ put Medusae, complejo de Edipo, ecografía, higiene), en la anatomía (Iris, atlas, tendón de Aquiles, Siringomielia) y en la nomenclatura farmacéutica (atropina, hipnótico, morfina).
Además de ser la mitología griega una fuente inagotable de epónimos, se debe recordar que muchos términos que empleamos se originaron de textos clásicos, cómo, por ejemplo, la palabra sepsis ( $\sigma \eta ́ \psi 1 \varsigma)$, la cual significa "carne podrida y putrefacta", y se encuentra en el canto XXIV de la Ilíada de Homero $^{20}$.

En la labor clínica cotidiana el uso de designaciones mitológicas puede servir como un punto de partida para las digresiones en la historia literaria, artística y médica con el fin de proporcionar una comprensión de las tradiciones culturales y mejorar la educación.

\section{Conflicto de intereses}

Los autores declaran no tener conflicto de intereses.

\section{Referencias}

1. Lips Castro W, Urenda Arias C. Medicine in the pre-hippocratic civilization of ancient greece. Gac Med Mex. 2014;150 Suppl 3:369-76.

2. Vons J. Gods, women and pharmacy in Greek Mythology. Rev Hist Pharm (Paris). 2001; 49(332):501-12.

3. Karenberg A. The worlds of gods in medicine. Z Rheumatol. 2017; 76(7): 630-5.

4. Shampo MA, Kyle RA. Karl Theodore Dussik-pioneer in ultrasound. Mayo Clin Proc. 1995; 70(12):1136.

5. Dussik, KT. Über die Möglichkeit, hochfrequente mechanische Schwingungen als diagnostisches Hilfsmittel zu verwerten. Zeitschrift für die gesamte Neurologie und Psychiatrie 1942; 174:153-68.

6. Ovidio. Las metamorfosis, Bruguera, Barcelona, 1983, Pan y Siringe, Libro primero, 689-712.

7. Demerdash A, Loukas M, Tubbs RS. La tragedia de Syrinx. Childs Nerv Syst. 2014;
30(3):371-3.

8. Vandertop WP. Syringomyelia. Neuropediatrics. 2014; 45(1):3-9.

9. Mortazavi MM, Rompala OJ, Verma K, Tubbs I, Tubbs RS, Cohen-Gadol AA. Charles Prosper Ollivier d'Angers (17961845) and his contributions to defining syringomyelia. Childs Nerv Syst. 2011; 27(12):2155-8

10. Ntaidou TK, Siempos II. The art of providing anaesthesia in Greek mythology. Anaesth Intensive Care. 2012; 40 Suppl 1:22-7.

11. Sertürner FW. Analyse de l'opium. De la morphine et de l'acide méconique, considérés comme parties essentielles de l'opium. Traduit par M. Rose, pharmacien à Berlin. Ann Chim Phys 1817;5:21-41.

12. López Pozo F. Diccionario españolgriego-latín. p. 289, 500, 511 y 652 . [Serial en internet]. Consultado el $1 \mathrm{de}$ septiembre de 2018. Disponible en: http:// www.culturaclasica.com.

13. Graf F. Apollo, God of Healing. En: Graf F. Apollo. Abingdon, Oxon: Taylor \& Francis Group/Routledge; 2009. p. 65-83.
14. Sanan A, van Loveren HR. The arachnoid and the myth of Arachne. Neurosurgery. 1999;45(1):152-5.

15. Hesíodo. Teogonía. Editorial Universidad Nacional Autónoma de México. Edición 2007, México D.F.

16. Laín Entralgo, P. La historia Clínica Hipocrática. Biblioteca Virtual Miguel de Cervantes, Alicante, 2017. Edición digital a partir de Archivos Iberoamericanos de Historia de la Medicina, núm. 1 (1949), pp. 9-48. Consultado el 21 septiembre 2018. Disponible en http://www. cervantesvirtual.com/nd/ark:/59851/ bmcrb947

17. Graves, R. Los Mitos Griegos. Editorial Ariel. Edición 2012, Barcelona.

18. Sófocles. Antígona. Editorial Universitaria. 28a. Edición, 2017, Santiago de Chile.

19. Rose H. Introduction: History of Mythology. En: Rose H. A Handbook of Greek Mythology. Londres/Nueva York: Taylor \& Francis e-Library; 2005. p. 1.

20. Homero. La Iliada. Canto XXIV. Verso 414. 